\title{
Conformational destabilization of Bacillus licheniformis a-amylase induced by lysine modification and calcium depletion
}

\author{
Cheau Yuaan Tan', Raja Noor Zaliha Binti Raja Abdul Rahman², Habsah Abdul Kadir \\ and Saad Tayyab ${ }^{1, \otimes}$
}

'Biomolecular Research Group, Biochemistry Programme, Institute of Biological Sciences, University of Malaya, Kuala Lumpur, Malaysia; ${ }^{2 D e p a r t-}$ ment of Microbiology, Faculty of Biotechnology and Biomolecular Sciences, University Putra Malaysia, Serdang, Selangor, Malaysia

\begin{abstract}
Bacillus licheniformis a-amylase (BLA) was chemically modified using 100-fold molar excess of succinic anhydride over protein or $0.66 \mathrm{M}$ potassium cyanate to obtain $42 \%$ succinylated and $81 \%$ carbamylated BLAs. Size and charge homogeneity of modified preparations was established by Sephacryl S-200 HR gel chromatography and polyacrylamide gel electrophoresis. Conformational alteration in these preparations was evident by the larger Stokes radii $(3.40 \mathrm{~nm}$ for carbamylated and $3.34 \mathrm{~nm}$ for succinylated BLAs) compared to $2.43 \mathrm{~nm}$ obtained for native BLA. Urea denaturation results using mean residue ellipticity (MRE) as a probe also showed conformational destabilization based on the early start of transition as well as $\Delta G_{D} H_{2} \mathrm{O}$ values obtained for both modified derivatives and Ca-depleted BLA. Decrease in $\Delta G_{D} H_{2} \mathrm{O}$ value from $5,930 \mathrm{cal} / \mathrm{mol}$ (for native $B L A$ ) to $3,957 \mathrm{cal} / \mathrm{mol}$ (for succinylated BLA), 3,336 cal/mol (for carbamylated BLA) and 3,430 cal/mol for Ca-depleted BLA suggested reduced conformational stability upon modification of amino groups of BLA or depletion of calcium. Since both succinylation and carbamylation reactions abolish the positive charge on amino groups (both $a$ - and $\varepsilon$ - amino), the decrease in conformational stability can be ascribed to the disruption of salt bridges present in the protein which might have released the intrinsic calcium from its binding site.
\end{abstract}

Keywords: BLA, calcium, conformation, lysine, salt bridges, stability, urea

Received: 28 April, 2011; revised: 11 July, 2011; accepted: 19 August, 2011; available on-line: 30 August, 2011

\section{INTRODUCTION}

In order to perform their biological functions, proteins fold into a specific conformation, driven by covalent (disulfide bridges) as well as non-covalent forces such as hydrogen bonds, hydrophobic packing, van der Waals and electrostatic interactions (Anfinsen, 1973). Although most proteins are mainly stabilized by hydrogen bonding and hydrophobic packing (Machius et al., 2003; Pace, 2009), electrostatic interactions between charged residues do contribute significantly towards maintaining native three-dimensional structure (Serrano et al., 1990; Singh \& Bhakuni, 2008). These charged residues (about $23 \%$ of the total number of amino-acid residues) are mostly distributed at the surface of a protein (Miller et al., 1987; Isom et al., 2010). Some highly thermostable proteins have attracted the attention of researchers to explore the role of different forces in their enhanced stability (Khajeh et al., 2001a; 2001b; Machius et al., 2003).

$\alpha$-Amylases $\quad(\alpha$-1,4-glucan-4-glucanohydrolases, $\quad$ EC 3.2.1.1), members of the family of endo-amylases, catalyze the hydrolysis of $\alpha$-D- $(1,4)$ glycosidic bonds yielding malto-oligosaccharides and glucose (Machius et al., 1995; Nazmi et al., 2006). Their biotechnological applications encompass maltodextrins and alcohol production, brewing, baking, textile and detergent industry (Pandey et al., 2000; Ammar et al., 2002; Varavinita et al., 2002; Bessler et al., 2003; Nagarajan et al., 2006). Being highly thermostable $\left(T_{m}\right.$ about $103^{\circ} \mathrm{C}$ ) (Fitter \& Haber-Pohlmeier, 2004), Bacillus licheniformis $\alpha$-amylase (BLA) is an enzyme of choice to be used in starch processing industry involving high temperature conditions (Janeček \& Baláž, 1992). Participation of a few salt bridges has been suggested to be responsible for the enhanced thermostability of BLA based on a comparative study on two homologous amylases, Bacillus amyloliquefaciens $\alpha$-amylase (BAA) and BLA (Tomazic \& Klibanov, 1988; Machius et al., 1995). Presence of five lysine residues at positions 88, 253, 308, 317 and 385 in the non-conserved regions of the primary sequence of BLA seems to offer greater thermostability to the enzyme (Tomazic \& Klibanov, 1988). In addition, substitutions of lysine residues at positions 88 , 253 and 385 of BLA with uncharged residues (glycine, alanine and asparagine) have been shown to decrease the thermostability of the enzyme, suggesting the role of the lysine residues in increasing thermostability of the enzyme through salt bridges (Tomazic \& Klibanov, 1988). Since thermostable proteins have also been found resistant toward chemical denaturation (Griffin et al., 2003), it would be of interest to study the role of electrostatic interactions (salt bridges) in the conformational stability of the enzyme against chemical denaturants. Chemical modification would be a useful approach to study the role of salt bridges in the conformational stability of BLA. Hence, lysine residues of BLA were modified using succinic anhydride (to convert the positive charge on lysine residues into negative charge) or potassium cyanate (to abolish the charge on lysine residues) and the effect of charge imbalance on the conformational stability of BLA was studied.

e-mail: saadtayyab2004@yahoo.com

Abbreviations: BAA, Bacillus amyloliquefaciens a-amylase; BLA, Bacillus licheniformis a-amylase; $C D$, circular dichroism; MRE, mean residue ellipticity; TNBSA, 2,4,6-trinitrobenzene sulfonic acid; $C_{81}$, $81 \%$ carbamylated $\mathrm{BLA} ; \mathrm{S}_{42}, 42 \%$ succinylated $\mathrm{BLA} ; \Delta G_{\mathrm{D}} \mathrm{H}_{2} \mathrm{O}$, free energy of stabilization 


\section{MATERIALS AND METHODS}

Materials. $\alpha$-Amylase from Bacillus licheniformis (BLA) (Lot 018K7008), various marker proteins such as bovine serum albumin (BSA) (Lot 015K0591), carbonic anhydrase (Lot 99H0669), $\alpha$-chymotrypsinogen A, type II (Lot 16H7075) and cytochrome $c$ (Lot 27H7065), Sephacryl S-200 HR, blue dextran and urea (SigmaUltra) were purchased from Sigma Chemical Co. (USA). Succinic anhydride and potassium cyanate were from Fluka (Germany). Tris base was obtained from AMRESCO ${ }^{\circledR}$ (USA) while 2,4,6-trinitrobenzene sulfonic acid (TNBSA) was the product of Pierce Chemical Company (USA). All other chemicals used were of analytical grade purity. All experiments were performed at $25^{\circ} \mathrm{C}$ unless stated otherwise.

Analytical procedures. Protein concentration was determined by the method of Lowry et al. (1951) using BSA as the standard. Method described by Pace and Scholtz (1997) was used to determine the concentration of stock urea solution. Absorbance measurements were made on a Shimadzu double-beam spectrophotometer, model UV-2450 (Japan), using cuvettes of $1 \mathrm{~cm}$ path length made of quartz glass for measurements in the UV range and polystyrene in the visible range.

Preparation of Ca-depleted BLA. Commercial preparation of native BLA was dissolved and dialyzed against $40 \mathrm{mM}$ Tris/20 mM EGTA buffer, pH 7.2 overnight with at least 3 changes (Nazmi et al., 2006). Subsequently, EGTA was removed from the sample by dialysis against $20 \mathrm{mM}$ Tris/ $\mathrm{HCl}$ buffer, $\mathrm{pH}$ 7.5. Each step was performed at $4{ }^{\circ} \mathrm{C}$ and plastic vessels were used instead of glass to prevent $\mathrm{Ca}^{2+}$ contamination.

\section{Chemical modifications of lysine residues}

Succinylation of BLA. Lysine residues of BLA were modified using 100-fold molar excess of succinic anhydride over protein according to the method of Klotz (1967) with slight modification. Succinic anhydride (90 $\mathrm{mg}$ ) dissolved in $1 \mathrm{ml}$ of dimethylsulfoxide was added in aliquots to a constantly stirred protein solution (500 $\mathrm{mg}$ BLA in $50 \mathrm{ml}$ of $0.06 \mathrm{M}$ sodium phosphate buffer, $\mathrm{pH} 7.5$ ) over a period of $15 \mathrm{~min}$ at $4^{\circ} \mathrm{C}$. The $\mathrm{pH}$ of the reaction mixture was maintained in the range of 7.5-8.0 with $1 \mathrm{M}$ sodium hydroxide and the reaction was continued for $1 \mathrm{~h}$. Upon completion, the protein solution was extensively dialyzed against $0.02 \mathrm{M}$ Tris/ $\mathrm{HCl}$ buffer, $\mathrm{pH}$ 7.5 for $48 \mathrm{~h}$.

Carbamylation of BLA. Carbamylation of BLA was performed following the procedure described by Stark (1967) using $0.66 \mathrm{M}$ potassium cyanate. To $62 \mathrm{ml}$ of BLA solution (about $10 \mathrm{mg} / \mathrm{ml}$ ) in $0.06 \mathrm{M}$ sodium phosphate buffer, $\mathrm{pH} 7.7,4.5 \mathrm{~g}$ of solid potassium cyanate was added successively within $30 \mathrm{~min}$ at $4{ }^{\circ} \mathrm{C}$ with continuous stirring. The reaction was carried out for $48 \mathrm{~h}$ at $4^{\circ} \mathrm{C}$ while maintaining the $\mathrm{pH}$ of the reaction mixture at 7.7-8.0 by addition of $0.2 \mathrm{M}$ acetic acid. After completion of the reaction, the protein solution was dialyzed against $0.02 \mathrm{M}$ Tris/ $\mathrm{HCl}$ buffer, $\mathrm{pH} 7.5$ with several changes for $48 \mathrm{~h}$.

Quantification of modification. Modified amino groups ( $\alpha$ - and $\varepsilon$-amino) were quantified using TNBSA color reaction as described by Habeeb (1966). Percentage of modification of amino groups was calculated by substituting the slope values $\left(\mathrm{m}_{\mathrm{o}}\right.$ and $\mathrm{m}$, obtained for native and modified BLAs respectively) in the formula, $1-\left(\mathrm{m} / \mathrm{m}_{\mathrm{o}}\right) \times 100$.
Detection of different charged states of BLA. Different charged states of BLA in modified derivatives were checked by electrophoresis on $10 \%$ polyacrylamide gel following the method of Laemmli (1970) under nondenaturing conditions. All solutions used in electrophoresis were devoid of sodium dodecyl sulfate. About $5 \mu \mathrm{g}$ of each protein was loaded into each well and staining of the gel was performed with Coomassie brilliant blue R-250 as described (Laemmli, 1970).

Detection of conformational changes. Conformational changes in different modified derivatives of BLA were monitored by analytical gel chromatography on a calibrated Sephacryl S-200 HR column $(1.63 \mathrm{~cm} \times 56$ $\mathrm{cm})$ equilibrated with $0.02 \mathrm{M}$ Tris $/ \mathrm{HCl}$ buffer, $\mathrm{pH} 7.5$ containing $0.02 \%$ sodium azide as described earlier (Khan \& Tayyab, 2001). Column calibration was performed with marker proteins of known Stokes radii (Salahuddin, 1991; Islam et al., 1994; Kallipolitou et al., 2001): BSA dimer (4.30 nm): BSA monomer (3.60 nm), carbonic anhydrase $(3.10 \mathrm{~nm}), \alpha$-chymotrypsinogen $\mathrm{A}$ $(2.24 \mathrm{~nm})$ and cytochrome $c(1.70 \mathrm{~nm})$. Values of distribution coefficient, $K_{\mathrm{d}}$, and available distribution coefficient, $K_{\mathrm{av}}$ for different marker proteins as well as native and modified BLAs were obtained from their elution volumes (Tayyab et al., 1991) and these data were then treated according to Ackers (1967) and Laurent and Killander (1964). Stokes radii of native and modified BLAs were calculated from straight line equations obtained for the above plots.

Urea denaturation of native and modified BLAs. Urea denaturation experiments were performed following the method described earlier (Halim et al., 2008) using $0.02 \mathrm{M}$ Tris $/ \mathrm{HCl}$ buffer, $\mathrm{pH}$ 7.5. To $0.5 \mathrm{ml}$ stock protein (native/modified BLA) solution (final concentration $=0.1 \mathrm{mg} / \mathrm{ml}$ ), different volumes of the buffer were added first followed by the addition of different volumes of stock urea solution $(10 \mathrm{M})$ to obtain the desired concentration of denaturant. The reaction mixture $(5.0 \mathrm{ml})$ was mixed thoroughly and incubated overnight at room temperature. Circular dichroism (CD) spectra in the far-UV region (200-250 nm) were recorded on a Jasco J-810 spectropolarimeter equipped with a thermostatically controlled cell holder under constant nitrogen flow. The instrument was calibrated with (+)-10-camphorsulfonic acid and the response time was $1 \mathrm{~s}$ with a scan speed of $100 \mathrm{~nm} / \mathrm{min}$. The spectra were recorded using a $0.2 \mathrm{~cm}$ path length cell, averaged over three scans and corrected with suitable blanks. Results were expressed as mean residue ellipticity (MRE) in deg. $\mathrm{cm}^{2} \cdot \mathrm{dmol}^{-1}$ using the relation: $\mathrm{MRE}=\theta_{\text {obs }} \times(\mathrm{MRW} /$ $10 \times l \times c)$, where $\theta_{\text {obs }}$ is the measured ellipticity at 222 $\mathrm{nm}$ in millidegrees; $l$ is the optical path length of the cell in $\mathrm{cm}$; $c$ is the protein concentration in $\mathrm{mg} / \mathrm{ml}$ and MRW is the mean residue weight (molecular weight of the protein divided by the total number of amino-acid residues). MRE data were transformed into relative MRE by taking the MRE value of the protein in the absence of denaturant as 100 .

Data analysis. Analysis of denaturation data was done following a two-state model as described earlier (Muzammil et al., 2000). Relative MRE values obtained at different urea concentrations were transformed into $F_{D}$ (apparent fraction of the denatured form) values using Eqn. (1).

$$
F_{D}=\frac{Y-Y_{N}}{Y_{D}-Y_{N}}
$$


where $\mathrm{Y}$ represents the MRE value at a given denaturant concentration and $Y_{N}$ and $Y_{D}$ are MRE values of the native and denatured states, respectively, obtained by the linear extrapolation of pre- and post-transition zones. Values of $\mathrm{F}_{\mathrm{D}}$ ranging from 0.20 to 0.80 were used to calculate apparent equilibrium constant, $K_{\mathrm{D}}$ following the given Eqn. (2).

$$
K_{\mathrm{D}}=\frac{\mathrm{F}_{\mathrm{D}}}{\left(1-\mathrm{F}_{\mathrm{D}}\right)}
$$

These $K_{\mathrm{D}}$ values were used to calculate the free energy change $\left(\Delta G_{\mathrm{D}}\right)$ using Eqn. (3).

$\Delta G_{\mathrm{D}}=-R T \ln K_{\mathrm{D}}$

where $R$ is the gas constant $(1.987 \mathrm{cal} \cdot \mathrm{deg} \cdot \mathrm{mol})$ and $\mathrm{T}$ is the absolute temperature $\left(273+25^{\circ} \mathrm{C}\right)$. Free energy of stabilization, $\Delta G_{\mathrm{D}}{ }^{\mathrm{H}_{2} \mathrm{O}}$, was determined from the y-axis intercept of the linear plot of $\Delta G_{\mathrm{D}}$ versus denaturant concentration [D] using least squares analysis which fitted the following Eqn. (4).

$\Delta G_{\mathrm{D}}=\Delta G_{\mathrm{D}} \mathrm{H}_{2} \mathrm{O}-m[\mathrm{D}]$

where $m$ is the slope value and is a measure of the dependence of $\Delta G_{\mathrm{D}}$ on denaturant concentration.

\section{RESULTS AND DISCUSSION}

\section{Chemical modifications of lysine residues}

Formation of yellow trinitrophenyl derivatives with an absorption maximum at $335 \mathrm{~nm}$ in TNBSA reaction with proteins was employed to quantify the modification of lysine residues in BLA (Habeeb, 1966). Figure 1 shows the results of TNBSA color reaction with native (N), succinylated (S) and carbamylated (C) BLAs, prepared by using succinic anhydride and potassium cyanate, respectively. Linear increase in absorbance at 335 $\mathrm{nm}$ was observed upon increasing protein concentration in all preparations. However, both modified preparations showed reduction in the slope value which was more pronounced in carbamylated BLA (Fig. 1, Table 1). Since TNBSA reacts with amino groups $(\alpha$-amino and $\varepsilon$-amino) of proteins, any reduction in the color intensity can be attributed to the modification of amino groups of proteins. Quantification of modification of amino groups of BLA in modified preparations resulted in the percentage of modification as $42 \%$ and $81 \%$ for succinylated and carbamylated preparations, respectively (Table 1).

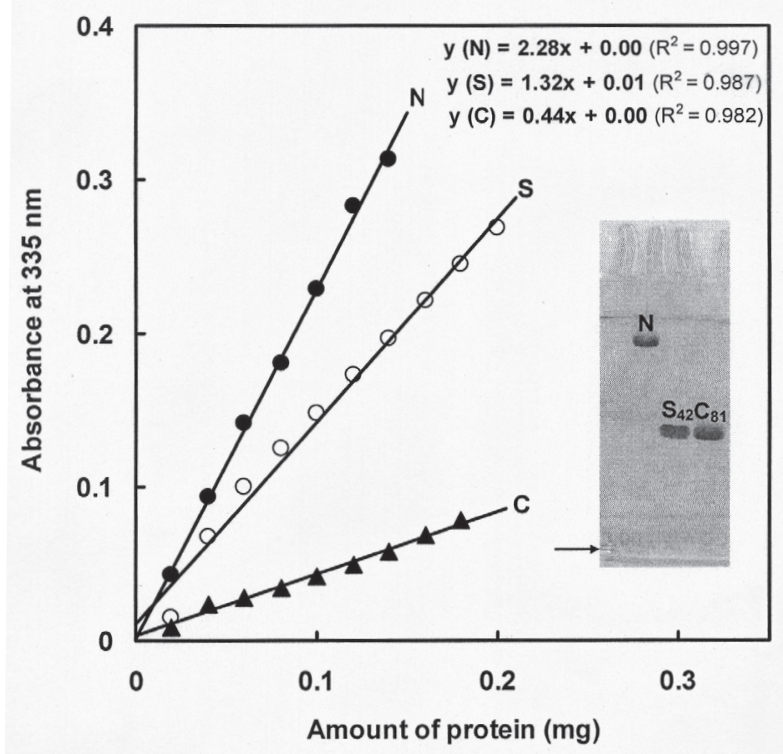

Figure 1. TNBSA color reaction to determine the extent of modification in succinylated and carbamylated BLA preparations Symbols ' $N$ ' $(\mathbf{O})$, ' $S$ ' $(O)$ and ' $C$ ' $(\boldsymbol{\Delta})$ refer to native, succinylated and carbamylated BLA preparations, respectively. Straight lines were drawn using least squares analysis. Inset shows PAGE pattern of native $(\mathrm{N}), 42 \%$ succinylated $\left(\mathrm{S}_{42}\right)$ and $81 \%$ carbamylated $\left(C_{81}\right)$ BLAs according to the method of Laemmli (1970) on $10 \%$ polyacrylamide gel. Arrow at the bottom shows the position of tracking dye.

A total of 12 and 24 amino groups were found to be modified in $42 \%$ succinylated $\left(\mathrm{S}_{42}\right)$ and $81 \%$ carbamylated $\left(\mathrm{C}_{81}\right)$ BLAs, respectively (Table 1$)$ by taking the total number of amino groups in BLA as $29(1 \alpha$-amino +28 $\varepsilon$-amino) (Tomazic \& Klibanov, 1988).

Charge homogeneity of modified BLAs was checked by polyacrylamide gel electrophoresis (PAGE) at $\mathrm{pH}$ 8.3, according to the method of Laemmli (1970). Inset of Fig. 1 shows the electrophoretic pattern of native $(\mathrm{N})$, succinylated $\left(\mathrm{S}_{42}\right)$ and carbamylated $\left(\mathrm{C}_{81}\right)$ BLAs on $10 \%$ polyacrylamide gel. The presence of a single major band in all lanes was indicative of charge homogeneity of all BLA preparations. Both $\mathrm{S}_{42}$ and $\mathrm{C}_{81}$ BLA preparations showed similar higher anodic mobilities (0.47) compared to 0.09 obtained with native BLA (Table 1). This was in accordance with the increase in the net negative charge of modified preparations. In view of the isoelectric point of native BLA of 6.0 (Shaw et al., 2008), the net charge on the protein would be negative at $\mathrm{pH} 8.3$ (conditions for PAGE), which can account for the anodic mobility

Table 1. Modification of amino groups of BLA

\begin{tabular}{|c|c|c|c|c|c|}
\hline BLA preparations & Reaction conditions & $\begin{array}{l}\text { Slope of TNBSA color } \\
\text { reaction }\end{array}$ & $\begin{array}{l}\text { Extent of modifica- } \\
\text { tion }(\%)\end{array}$ & $\begin{array}{l}\text { No. of amino groups } \\
\text { modified }^{*}\end{array}$ & $\begin{array}{l}\text { Relative mobility } \\
\left(R_{m}\right)\end{array}$ \\
\hline Native & - & 2.28 & 0 & 0 & 0.09 \\
\hline Succinylated & $\begin{array}{l}\text { 100-fold molar } \\
\text { excess of succinic } \\
\text { anhydride, } 1 \mathrm{~h}, \mathrm{pH} \\
7.5,4{ }^{\circ} \mathrm{C}\end{array}$ & 1.32 & 42 & 12 & 0.47 \\
\hline Carbamylated & $\begin{array}{l}0.66 \mathrm{M} \text { potassium } \\
\text { cyanate, } 48 \mathrm{~h}, \mathrm{pH} \\
7.7-8.0,4^{\circ} \mathrm{C}\end{array}$ & 0.44 & 81 & 24 & 0.47 \\
\hline
\end{tabular}

"Total number of amino groups was taken as 29 (1 a-amino + 28 -amino groups) (Tomazic \& Klibanov, 1988) 


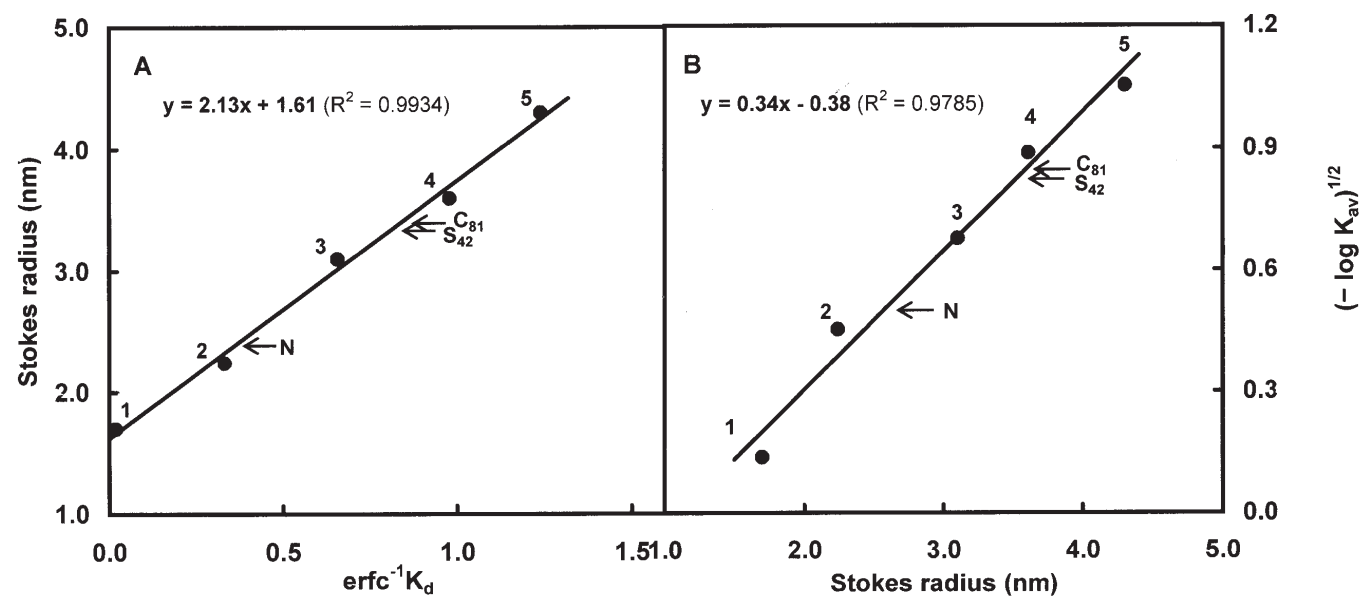

Figure 2. A, Ackers' plot and B, Laurent and Killander's plot for determination of Stokes' radii of native, succinylated and carbamylated BLAs

Numbers 1-5 refer to different marker proteins: 1 . cytochrome $c$; 2 . a-chymotrypsinogen $A$; 3. carbonic anhydrase; 4 . BSA monomer and 5. BSA dimer. Positions of native $(\mathrm{N})$ and modified $\left(\mathrm{S}_{42}\right.$ and $\left.\mathrm{C}_{81}\right)$ BLAs are shown by arrows. Straight lines were drawn using least squares analysis.

of native BLA. Since succinylation increases the net negative charge on the protein by 2 units per amino group modified against the increase of 1 unit in carbamylation reaction, the succinylated preparation would have a stronger net negative charge compared to the carbamylated derivative. However, the extent of modification in the succinylated preparation was about half that of $\mathrm{C}_{81}$ BLA, thus the net negative charge in both preparations would have been similar but higher than that of native BLA which can account for the same relative mobility observed with these preparations. Size homogeneity of native and modified BLA preparations was confirmed by their elution profiles (in the form of single symmetrical peak) on Sephacryl S-200 HR column (not shown).

\section{Conformational changes in modified BLAs}

Stokes radii of native and modified BLAs were determined by analytical gel chromatography on a calibrated Sephacryl S-200 HR column equilibrated with $0.02 \mathrm{M}$ Tris/ $\mathrm{HCl}$ buffer, $\mathrm{pH} 7.5$, to examine the effect of succinylation and carbamylation on the conformation of BLA. Void volume, $\mathrm{V}_{\mathrm{o}}$, and inner volume, $\mathrm{V}_{\mathrm{i}}$ of the column were determined to be 46.5 and $69 \mathrm{ml}$, respectively, whereas different marker proteins, i.e. cytochrome $c, \alpha$-chymotrypsinogen $\mathrm{A}$, carbonic anhydrase, BSA monomer and BSA dimer had elution volumes of 114, 90.5, 71, 58 and $52 \mathrm{ml}$, respectively. Both modified BLA preparations eluted much earlier than native BLA, with elution volumes of 65 and $63 \mathrm{ml}$ for $S_{42}$ and $C_{81}$

Table 2. Stokes radii of native, succinylated and carbamylated BLAs at $\mathrm{pH} 7.5$

\begin{tabular}{llll}
\hline & \multicolumn{2}{l}{ Stokes radius $(\mathrm{nm})$} \\
\cline { 2 - 4 } $\begin{array}{l}\text { BLA } \\
\text { preparations }\end{array}$ & From Eqn. 5 & From Eqn. 6 & Mean \\
\hline Native & 2.37 & 2.48 & 2.43 \\
$\mathrm{~S}_{42}$ & 3.31 & 3.36 & 3.34 \\
$\mathrm{C}_{81}$ & 3.38 & 3.42 & 3.40 \\
\hline
\end{tabular}

BLAs, respectively, compared to $89 \mathrm{ml}$, obtained for native BLA. The decrease in elution volume $(24-26 \mathrm{ml}$ ) of the modified BLA derivatives was suggestive of an increase in the hydrodynamic volume of these preparations (Datta \& Mohan Rao, 2000). Values of the elution volumes of marker proteins and native, $S_{42}$ and $C_{81}$ BLA preparations were transformed into $K_{\mathrm{d}}, K_{\mathrm{av}}^{4},\left(-\log K_{\mathrm{av}}\right)^{1 / 2}$ and $\operatorname{erfc}^{-1} K_{\mathrm{d}}$ values according to standard procedures as described elsewhere (Tayyab et al., 1991). Figure 2A and B shows linear plots drawn following the methods of Ackers (1967) and Laurent and Killander (1964), respectively, which yielded the following straight line Eqns.

Stokes radius, $\mathrm{nm}=2.13 \mathrm{erfc}^{-1} K_{\mathrm{d}}+1.61$

$\left(-\log K_{\mathrm{av}}\right)^{1 / 2}=0.34$ Stokes radius, $\mathrm{nm}-0.38$

Substitution of $\operatorname{erfc}^{-1} K_{\mathrm{d}}$ and $\left(-\log K_{\mathrm{av}}\right)^{1 / 2}$ values of native, $\mathrm{S}_{42}$ and $\mathrm{C}_{81}$ BLAs into Eqns. (5) and (6) yielded Stokes radii of these preparations which along with the mean values are shown in Table 2. The Stokes radius of native BLA $(2.43 \mathrm{~nm})$ as obtained from gel chromatographic data was lower than the value $(3.20 \mathrm{~nm})$ determined from dynamic light scattering (Fitter \& HaberPohlmeier, 2004). Such anomalous behavior of BLA on gel chromatographic column was not surprising as interaction of $\alpha$-amylases with various gel matrices has been reported earlier (Kruger \& Lineback, 1987). Irrespective of this anomalous behavior, useful information about the change in hydrodynamic volume can be obtained by comparing the Stokes radii of modified proteins to their native form. The decrease in elution volumes of succinylated $(65 \mathrm{ml})$ and carbamylated $(63 \mathrm{ml})$ BLAs compared to native BLA $(89 \mathrm{ml})$ suggested an increase in the molecular size of these modified derivatives which was verified from their Stokes radii $\left[\mathrm{S}_{42}(3.34 \mathrm{~nm})\right.$ and $\left.\mathrm{C}_{81}(3.40 \mathrm{~nm}) \mathrm{BLAs}\right]$ which were higher than their native counterpart (Table 2). $\mathrm{C}_{81}$ BLA showed a larger Stokes radius than $\mathrm{S}_{42}$ BLA which seems appropriate in view of the higher extent of modification in the carbamylated preparation.

The increase in the hydrodynamic volume of BLA upon succinylation and carbamylation as revealed by the increase in Stokes radius of native BLA from $2.43 \mathrm{~nm}$ to 3.34 and $3.40 \mathrm{~nm}$, respectively (Table 2), was in agree- 
ment with several previous reports on succinylation- and carbamylation-induced conformational changes in different proteins (Habeeb, 1967; Beswick \& Harding, 1984; Qin et al., 1992; Tayyab et al., 1999; Khan \& Tayyab, 2001; Derham \& Harding, 2002). Succinylation of lysine residues converts a positively-charged amino group into a negatively-charged succinyl group, thus increases the net negative charge on the protein by 2 units, whereas carbamylation neutralizes the positive charge on lysine residues and therefore the increase in net negative charge on the protein is 1 unit per lysine residue modified (Klotz, 1967; Stark, 1967). In view of this, both succinylated and carbamylated BLAs would have a stronger net negative charge and higher electrostatic free energy than native BLA which was responsible for the gross conformational changes observed in these modified preparations, leading to their conformational destabilization. Although the increase in the net negative charge on $\mathrm{S}_{42}$ and $\mathrm{C}_{81}$ BLAs would be the same $\left(2 \times 12=24\right.$ in $\mathrm{S}_{42}$ and $1 \times 24=24$ in $\mathrm{C}_{81}$ ), the conformational alteration observed in $\mathrm{C}_{81} \mathrm{BLA}$ was slightly higher than that in $\mathrm{S}_{42}$ BLA. This is because only 12 amino groups were modified in $\mathrm{S}_{42}$ BLA against 24 modified in $\mathrm{C}_{81}$ BLA. In other words, $\mathrm{C}_{81}$ BLA had both surface-exposed and partially buried lysine residues modified compared to the modification of only surfaceexposed lysine residues in $\mathrm{S}_{42}$ BLA. Modification of these partially buried lysine residues in $\mathrm{C}_{81}$ BLA would have destabilized the native conformation more than did the modification of surface-exposed lysine residues in $\mathrm{S}_{42}$ BLA.

\section{Conformational stabilities of native and modified BLAs}

To investigate the effect of chemical modification on the conformational stability of native and modified BLAs, urea denaturation of these proteins was studied in $0.02 \mathrm{M}$ Tris/ $\mathrm{HCl}$ buffer, $\mathrm{pH} 7.5$, using $\mathrm{CD}$ spectral signal in the far-UV range (MRE at $222 \mathrm{~nm}$ ) to monitor the changes in secondary structure of the proteins (Singh \& Bhakuni, 2008). Since BLA contains three calcium-binding sites (Machius et al., 1998) and bound calcium has been reported to offer structural stability to the enzyme (Vihinen \& Mäntsälä, 1989; Violet \& Meunier, 1989; Feller et al., 1999; Tan et al., 2010), we thought it of interest to study the conformational stability of commercially available BLA (partially saturated with calcium) both before and after depleting calcium from it and compared urea denaturation profiles of these enzymes. Figure $3 \mathrm{~A}$ shows urea-induced denaturation of native (commercially available enzyme, partially saturated with calcium) and Ca-depleted BLA (apoenzyme) as followed by MRE measurements at $222 \mathrm{~nm}$. In order to rule out the effect of concentration (if any), MRE values at $222 \mathrm{~nm}$ were transformed into relative MRE and plotted against urea

Table 3. Urea denaturation of native, succinylated and carbamylated BLAs at $\mathrm{pH} 7.5$ as monitored by MRE at $222 \mathrm{~nm}$

\begin{tabular}{lllll}
\hline \multirow{2}{*}{ BLA preparations } & \multicolumn{2}{l}{ Transition } & & \multicolumn{2}{c}{$\Delta \mathrm{G}_{\mathrm{H}_{2} \mathrm{O}}$} \\
\cline { 2 - 4 } & Start-point [M] & Mid-point [M] & End-point [M] & \\
\hline Native & 3.50 & 6.25 & 7.50 & 5,930 \\
Ca-depleted & 1.00 & 3.25 & 4.50 & 3,430 \\
$\mathrm{~S}_{42}$ & 2.50 & 5.00 & 7.50 & 3,957 \\
$\mathrm{C}_{81}$ & 1.00 & 3.25 & 4.50 & 3,336 \\
\hline
\end{tabular}

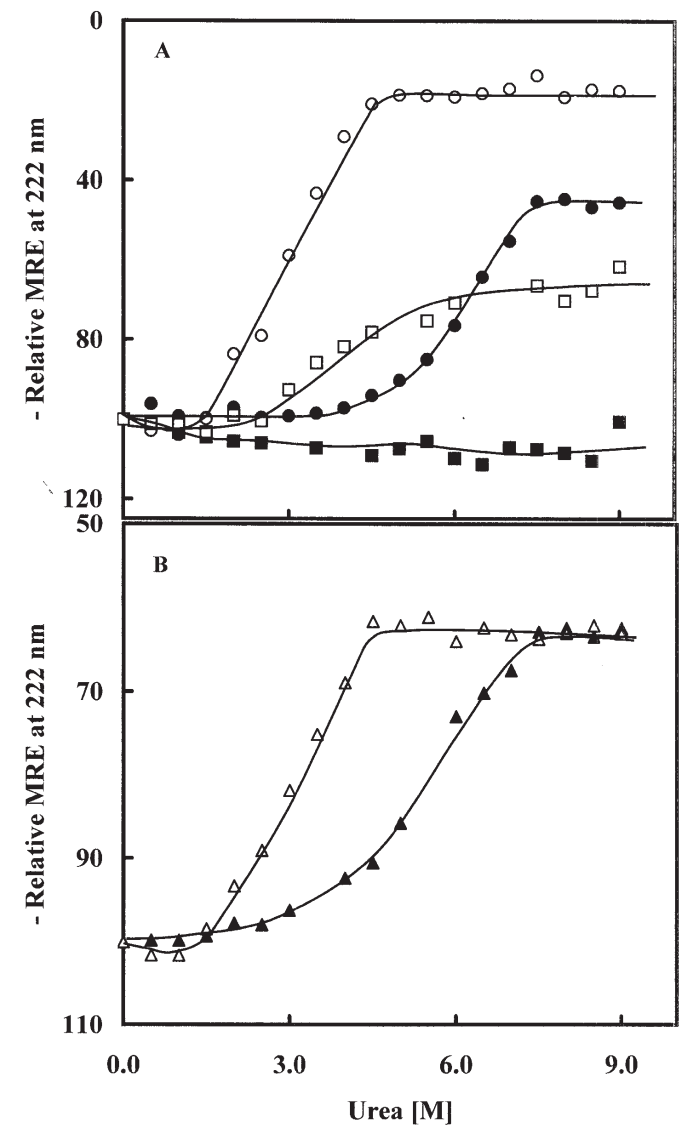

Figure 3. Plots of relative MRE at $222 \mathrm{~nm}$ versus urea concentration

(A) Native BLA in the absence $(0)$ and presence of $2 \mathrm{mM} \mathrm{CaCl}$ ) and Ca-depleted BLA in the absence $(O)$ and presence of 2 $\mathrm{mM} \mathrm{CaCl}(\square) ;(B) \mathrm{S}_{42}(\mathbf{\Delta})$ and $\mathrm{C}_{81}(\triangle)$ BLA preparations.

concentration. As can be seen from the figure, there was a decrease in MRE value on increasing the urea concentration in both preparations being more pronounced and starting earlier in Ca-depleted BLA compared to native BLA. Denaturation of both proteins followed a singlestep, two-state transition model. The transition curve of Ca-depleted BLA started at $1.0 \mathrm{M}$ urea and completed at $4.5 \mathrm{M}$ with a mid-point at $3.25 \mathrm{M}$ (Fig. 3A, Table 3). Furthermore, the decrease in MRE value at the completion of transition was approx. $83 \%$. These results were in agreement both in terms of percentage decrease of MRE at the completion of transition and the start point with the only report available on urea denaturation of Ca-depleted BLA (Nazmi et al., 2006). However, both mid- and end-points of the transition observed in this study were slightly higher than the reported values. These differences might be due to the different reaction conditions ( $\mathrm{pH}$ and temperature) used in this study. On the other hand, the transition curve of native BLA (partially saturated with calcium) had the start-, mid- and end-points as $3.5,6.25$ and $7.5 \mathrm{M}$, respectively (Fig. 3A, Table 3). The shift of the transition curve of native BLA towards higher urea concentrations was suggestive of higher stability 


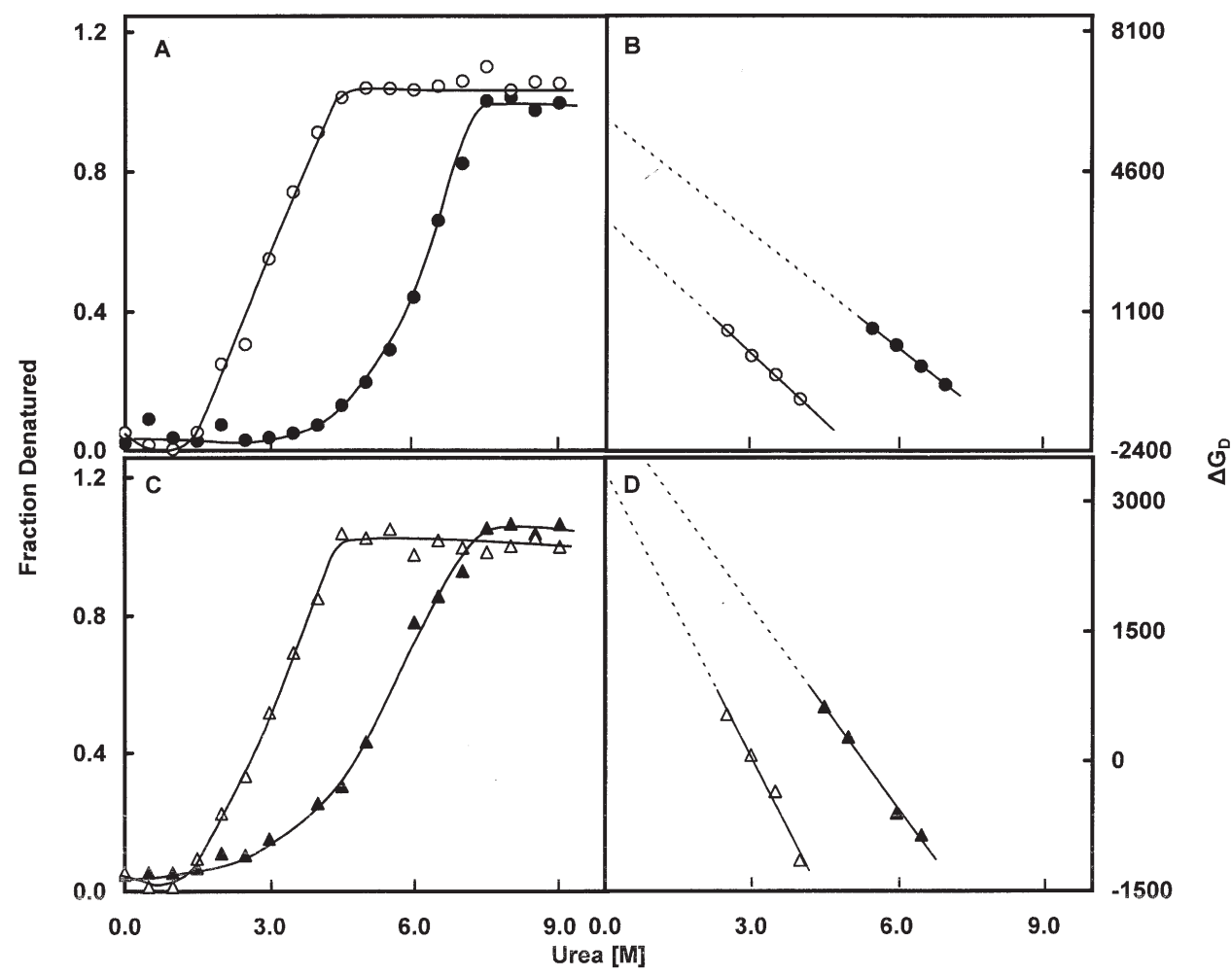

Figure 4. Normalized transition curves for urea denaturation in terms of $F_{0}$ versus urea concentration

A, native $(\mathbf{O})$ and $\mathrm{Ca}$-depleted $(\mathrm{O}) \mathrm{BLAs} ; \mathbf{C}, \mathrm{S}_{42}(\mathbf{\Delta})$ and $\mathrm{C}_{81}(\triangle)$ BLAs. Plots of $\Delta G_{\mathrm{D}}$ against urea concentration for the transitions of B, native $(\mathbf{O})$ and Ca-depleted $(\mathrm{O}) ; \mathbf{D}, \mathrm{S}_{42}(\mathbf{\Delta})$ and $\mathrm{C}_{81}(\triangle)$ BLAs.

of native BLA against urea denaturation compared to Ca-depleted BLA. This was in agreement with a previous report suggesting calcium-induced structural stabilization of BLA (Vihinen \& Mäntsälä, 1989; Violet \& Meunier, 1989; Feller et al., 1999; Kumari et al., 2010). However, the decrease in MRE value at the completion of transition was only $55 \%$ (Fig. 3A). This decrease was by 28 percentage points lower than the decrease observed with Ca-depleted BLA. The decrease in MRE value at 222 $\mathrm{nm}$ was indicative of the loss of $\alpha$-helical content in the proteins (Du \& Wang, 2003; Naoe et al., 2004). In view of this, the lesser decrease in native BLA at the completion of transition suggested retention of some $\alpha$-helical structures, stabilized by bound calcium in native BLA. This seems possible as all three calcium binding sites involve some contribution from domain A which contains all the eight segments of $\alpha$-helices present in BLA (Machius et al., 1998).

In an earlier study, native BLA has been shown to be resistant against urea denaturation even at the highest urea concentration (Nazmi et al., 2006). However, we noticed a cooperative urea transition in native BLA with a $55 \%$ decrease in MRE at the completion of transition (Fig. 3A). A smaller change in MRE (25\%) observed in an earlier study (Nazmi et al., 2006), compared to 55\% shown in this study, can be attributed to the different amount of bound calcium available in these preparations (Kumari et al., 2010). This seems understandable as these preparations were obtained from different companies, Novozymes and Sigma, respectively, which might have used different purification strategies. This is justifiable by our urea denaturation results on Ca-depleted BLA in the presence of $2 \mathrm{mM} \mathrm{CaCl}_{2}$ shown in Fig. 3A. The presence of $2 \mathrm{mM} \mathrm{CaCl}_{2}$ in the incubation mixture moved the onset of transition to a higher urea concentration with a change in MRE of about $30 \%$ at the highest urea concentration compared to $83 \%$ observed with the same preparation but in the absence of calcium. This was further supported by our results on urea denaturation of native BLA in the presence of $2 \mathrm{mM} \mathrm{CaCl}_{2}$ where the enzyme was found to be completely resistant towards urea denaturation. In view of this, the $25 \%$ change in MRE observed with native BLA in an earlier study (Nazmi et al., 2006) suggested the presence of a greater amount of bound calcium in their preparation. Taken together, a comparison of urea transitions obtained with Ca-depleted and native BLAs both in the absence and presence of $2 \mathrm{mM} \mathrm{CaCl}$, suggested a stabilizing effect of calcium towards urea denaturation of BLA. The enhanced stability in the presence of $2 \mathrm{mM} \mathrm{CaCl}_{2}$ could be due to the more compact surface of the enzyme formed upon saturation of calcium binding sites which prevented penetration of water to induce local and global destabilization (Machius et al., 2003). Such a phenomenon of compact surface limiting urea-induced denaturation has also been observed with a serine protease, milin (Yadav \& Jagannadham, 2009).

Similar single-step, two-state transitions were observed for both $\mathrm{S}_{42}$ and $\mathrm{C}_{81}$ BLA preparations (Fig. 3B). However, both transitions differed significantly in terms of start-, mid- and end-points of transition. For example, urea transition of $\mathrm{S}_{42}$ BLA started at $2.5 \mathrm{M}$ and ended at 7.5 M with a mid-point occurring at $5.0 \mathrm{M}$ urea. On the other hand, urea transition of $\mathrm{C}_{81}$ BLA started and ended much earlier, at $1.0 \mathrm{M}$ and $4.5 \mathrm{M}$, respectively, with the mid-point at $3.25 \mathrm{M}$ (Table 3). Since both modified preparations $\left(\mathrm{S}_{42}\right.$ and $\mathrm{C}_{81}$ BLAs) were prepared from native BLA, it would be logical to compare their transition curves with the transition curve obtained for native BLA. A comparison of these BLA preparations (native, $S_{42}$ and 
$\mathrm{C}_{81}$ BLAs) suggested a shift in the transition curve towards the left (lower urea concentrations) in both modified preparations which indicated lower conformational stability of these modified preparations, being more pronounced for $\mathrm{C}_{81}$ BLA. In view of the modification of 11 out of 28 lysine residues in $\mathrm{S}_{42}$ preparation compared to 23 out of 28 lysine residues in $\mathrm{C}_{81}$ BLA, the relatively lower stability of $\mathrm{C}_{81}$ BLA is justifiable as it might have contained some modified buried lysine residues as well. Interestingly, the urea transition characteristics of $\mathrm{C}_{81}$ BLA matched very well the transition characteristics of Ca-depleted BLA. In other words, the conformational stabilities of $\mathrm{C}_{81}$ BLA and Ca-depleted BLA seem to be similar.

Considering the location of the calcium binding site in the metal triad at the interface between domains A and $\mathrm{B}$ with high negative charge density (Machius et al., 1998), it seems likely that modification of lysine residues in $\mathrm{C}_{81}$ preparation might have disrupted the charge balance at the interface of these domains and thus caused the release of calcium from the metal binding site in this preparation. In an earlier report, the presence of a cis peptide bond between Trp184 and Glu185 has been suggested to be important for maintaining the correct structure of the metal binding site. Lys276 has also been proposed to stabilize the cis peptide bond conformation through an ionic interaction with Glu185 (Machius et al., 1998). It appears likely that $C_{81}$ BLA had Lys 276 modified resulting in the disruption of the calcium binding site. Together, both these explanations seem to be in favor of the disruption of the calcium binding site in $\mathrm{C}_{81}$ BLA which might be responsible for the release of calcium leading to the similarity of the urea transition curve of $\mathrm{C}_{81} \mathrm{BLA}$ to that of Ca-depleted BLA. The absence of such phenomenon in $\mathrm{S}_{42}$ BLA can be explained on the basis of lesser extent of modification which might have not modified the critical lysine residue(s) responsible for the stability of the calcium binding site. Our gel chromatographic data supported this contention as $\mathrm{C}_{81}$ BLA showed larger conformational change compared to $\mathrm{S}_{42}$ BLA (Table 2). The lower decrease in MRE observed with both modified preparations at the completion of transition may be the result of the loss of asymmetric environment of aromatic-amino acid residues at higher urea concentration in these preparations (Boren et al., 1999).

The urea denaturation data of native and modified BLA preparations were analyzed using a two-state model by converting $\mathrm{MRE}_{222 \mathrm{~nm}}$ values at each urea concentration into $\mathrm{F}_{\mathrm{D}}$ (fraction denatured) values as described in Materials and Methods. Figure 4 shows plots of $F_{D}$ values against urea concentration for native and $\mathrm{Ca}$-depleted BLAs (Fig. 4A) and the $\mathrm{S}_{42}$ and $\mathrm{C}_{81}$ BLA preparations (Fig. 4C). It should be noted that the values for start-, mid- and end-points of transitions remained the same as described above (Table 3). Values of $\mathrm{F}_{\mathrm{D}}$ (falling in the range $0.20-0.80$ ) were transformed into $K_{\mathrm{D}}$ and subsequently into $\Delta G_{\mathrm{D}}$ values at each urea concentration in order to quantify the loss in conformational stability of BLA induced by these modifications. Figures 4B and $4 \mathrm{D}$ show corresponding linear plots of $\Delta \mathrm{G}_{\mathrm{D}}$ against urea concentration for native and modified preparations, respectively. Values of free energy of stabilization $\left(\Delta G_{D} H_{2} \mathrm{O}\right)$ for native and modified preparations were determined from the $\mathrm{y}$-axis intercept of these linear plots and are given in Table 3. Native BLA had a $\Delta G_{D}{ }^{H_{2} \mathrm{O}}$ value of $5,930 \mathrm{cal} / \mathrm{mol}$ (Table 3), which was in agreement with the $\Delta G_{\mathrm{D}}{ }^{\mathrm{H}_{2} \mathrm{O}}$ values $(5-10 \mathrm{kcal} / \mathrm{mol})$ reported for a large number of globular proteins (Pace, 1995). Removal of calcium from native BLA had a marked influence on its stability as the $\Delta G_{\mathrm{D}} \mathrm{H}_{2} \mathrm{O}$ value was reduced significantly to $3,430 \mathrm{cal} / \mathrm{mol}$ (Table 3$)$. This value of $\Delta G_{\mathrm{D}} \mathrm{H}_{2} \mathrm{O}$ of Ca-depleted BLA was similar to a previously published value (Nazmi et al., 2006) although the earlier report did not mention a $\Delta G_{\mathrm{D}}{ }^{\mathrm{H}_{2} \mathrm{O}}$ value of native BLA (partially saturated with calcium). This decrease in $\Delta G_{\mathrm{D}} \mathrm{H}_{2} \mathrm{O}$ value observed with Ca-depleted BLA further confirmed our urea transition results shown in Fig. $3 \mathrm{~A}$ where Ca-depleted BLA showed a shift towards lower urea concentration, suggesting lower stability. Both modified preparations $\left(\mathrm{S}_{42}\right.$ and $\mathrm{C}_{81}$ BLAs) also had lower $\Delta G_{\mathrm{D}} \mathrm{H}_{2} \mathrm{O}$ values, i.e., 3,957 and $3,336 \mathrm{cal} / \mathrm{mol}$ for $\mathrm{S}_{42}$ and $\mathrm{C}_{81}$ BLAs, respectively (Table 3 ), compared to native BLA, which was suggestive of lower conformational stability of these modified preparations. Interestingly, the $\Delta G_{\mathrm{D}} \mathrm{H}_{2} \mathrm{O}$ value obtained with $\mathrm{C}_{81}$ BLA was similar to the $\Delta G_{\mathrm{D}}{ }^{\mathrm{H}_{2} \mathrm{O}}$ value for Ca-depleted BLA which was in line with our urea transition curves (Fig. 3). Taken together, all these results suggest the importance of lysine residues in maintaining the three-dimensional structure of BLA through salt bridges which in turn stabilize the calcium binding sites. This is understandable as both modified preparations showed an increase in hydrodynamic volume with concomitant decrease in conformational stability supported by the similar $\Delta G_{\mathrm{D}} \mathrm{H}_{2} \mathrm{O}$ values between $\mathrm{C}_{81}$ and Ca-depleted BLAs, suggesting loss of calcium binding sites in modified preparations. Thermostability of BLA has also been shown to involve domain $B$ and its interface with domain A containing a $(\beta / \alpha)_{8}$ barrel which in turn is governed by the catalytic triad $\mathrm{Ca}-\mathrm{Na}-\mathrm{Ca}$. The metal binding sites of these ions are influenced by alterations (e.g., mutation of specific amino-acid residue or chemical modification) which modify ionic interactions (Machius et al., 1995; Declerck et al., 2000). Perturbation to these interactions leads to the removal of critical calcium ions thus decreasing the enzyme's thermostability. Therefore, the salt bridges required to maintain the calcium binding sites in BLA have been found important not only in offering thermostability but also resistance against urea denaturation, as demonstrated in this study.

\section{Acknowledgements}

This project was funded in the form of Fundamental Research Grant Scheme (FP081/2007C) from the Ministry of Higher Education, Malaysia, to S.T. C.Y.T. acknowledges the financial support in the form of University Malaya Fellowship. S.T. is a member of CRYSTAL research group.

We are grateful to Professor Rosli Hashim, Head, Institute of Biological Sciences and Professor Dato' Dr. Mohd. Sofian Azirun, Dean, Faculty of Science for providing all the necessary facilities and working atmosphere. The authors acknowledge C. F. Wong for his help in the use of CD spectropolarimeter at Universiti Putra Malaysia.

\section{REFERENCES}

Ackers GK (1967) A new calibration procedure for gel filtration columns. J Biol Chem 242: 3237-3238.

Ammar YB, Matsubara T, Ito K, Iizuka M, Limpaseni T, Pongsawasdi P, Minamiura N (2002) New action pattern of a maltose-forming alpha-amylase from Streptomyces sp. and its possible application in bakery. J Biochem Mol Biol 35: 568-575.

Anfinsen CB (1973) Principles that govern the folding of protein chains. Science 181: 223-230. 
Bessler C, Schmitt J, Maurer KH, Schmid RD (2003) Directed evolution of a bacterial alpha-amylase: Toward enhanced $\mathrm{pH}$-performance and higher specific activity. Protein Sci 12: 2141-2149.

Beswick HT, Harding JJ (1984) Conformational changes induced in bovine lens alpha-crystallin by carbamylation. Relevance to cataract. Biochem J 223: 221-227.

Boren K, Anderson P, Larsson M, Carlsson U (1999) Characterization of a molten globule state of bovine carbonic anhydrase III: Loss of asymmetrical environment of the aromatic residues has a profound effect on both the near- and far-UV CD spectrum. Biochim Biophys Acta 1430: 111-118.

Datta SA, Mohan Rao CH (2000) Packing-induced conformational and functional changes in the subunits of $\alpha$-crystallin. J Biol Chem 275: 41001-41010.

Declerck N, Machius M, Wiegand G, Huber R, Gaillardin C (2000) Probing structural determinants specifying high thermostability in Bacillus licheniformis $\alpha$-amylase. J Mol Biol 301: 1041-1057.

Derham BK, Harding JJ (2002) Effects of modifications of $\alpha$-crystallin on its chaperone and other properties. Biochem J 364: 711-717.

Du Z, Wang X (2003) Effects of zinc on the activity and conformational changes of arginine kinase and its intermediate. J Biochem Mol Biol 36: 359-366.

Feller G, d'Amico D, Gerday C (1999) Thermodynamic stability of a cold-active alpha-amylase from the Antarctic bacterium Alteromonas baloplanctis. Biochemistry 38: 4613-4619.

Fitter J, Haber-Pohlmeier S (2004) Structural stability and unfolding properties of thermostable bacterial $\alpha$-amylases: A comparative study of homologous enzymes. Biochemistry 43: 9589-9599.

Griffin S, Higgins CL, Soulimane T, Wittung-Stafshede P (2003) High thermal and chemical stability of Thermus thermophilus seven-iron ferredoxin. Linear clusters form at high $\mathrm{pH}$ on polypeptide unfolding. Eur I Biochem 270: 4736-4743.

Habeeb AFSA (1966) Determination of free amino groups in proteins by trinitrobenzenesulfonic acid. Anal Biochem 14: 328-336.

Habeeb AFSA (1967) Quantification of conformational changes on chemical modification of proteins: Use of succinylated proteins as model. Arch Biochem Biophys 12: 652-664.

Halim AAA, Kadir HA, Tayyab S (2008) Bromophenol blue binding as a probe to study urea and guanidine hydrochloride denaturation of bovine serum albumin. J Biochem 144: 33-38.

Islam M, Qamar S, Tayyab S (1994) Involvement of lysine residues of goat serum albumin in high-affinity binding of bilirubin. Biochim Biophys Acta 1205: 171-177.

Isom DG, Castañeda CA, Cannon BR, Velu PD, García-Moreno EB (2010) Charges in the hydrophobic interior of proteins. Proc Natl Acad Sci USA 107: 16096-16100.

Janeček Š, Baláž Š (1992) $\alpha$-Amylases and approaches leading to their enhanced stability. FEBS Lett 304: 1-3.

Kallipolitou A, Deluca D, Majdic U, Lakämper S, Cross R, Meyhöfer E, Moroder L, Schliwa M, Woehlke G (2001) Unusual properties of the fungal conventional kinesin neck domain from Neurospora crassa. EMBO J 20: 6226-6235.

Khajeh K, Naderi-Manesh H, Ranjbar B, Moosavi-Movahedi, NematGorgani M (2001a) Chemical modification of lysine residues in Bacillus $\alpha$-amylases: effect on activity and stability. Ensyme Microb Technol 28: 543-549.

Khajeh K, Ranjbar B, Naderi-Manesh H, Habibi AE, Nemat-Gorgani M (2001b) Chemical modification of bacterial $\alpha$-amylases: changes in tertiary structures and the effect of additional calcium. Biochim Biophys Acta 1548: 229-237.

Khan MM, Tayyab S (2001) Understanding the role of internal lysine residues of serum albumins in conformational stability and bilirubin binding. Biochim Biophys Acta 1545: 263-277.

Klotz IM (1967) Succinylation. Methods Enyymol 11: 576-580.

Kruger JE, Lineback DR (1987) Carbohydrate degrading enzymes in cereals. In Ensymes and their role in the cereal technology. Kruger JE, Lineback DR, Stautter CE, eds, pp 117-139. AACC, St. Paul. Minnesota, USA.

Kumari A, Rosenkranz T, Kayastha AM, Fitter J (2010) The effect of calcium binding on the unfolding barrier: A kinetic study on homologous $\alpha$-amylases. Biophys Chem 151: 54-60.

Laemmli UK (1970) Cleavage of structural proteins during the assembly of the head of bacteriophage T4. Nature 227: 680-685.

Laurent TC, Killander J (1964) A theory of gel-filtration and its experimental verification. J Chromatogr 14: 317-330.
Lowry OH, Rosebrough NJ, Farr AL, Randall RJ (1951) Protein measurement with the Folin phenol reagent. J Biol Chem 193: 265-275.

Machius M, Declerck N, Huber R, Wiegand G (1998) Activation of Bacillus licheniformis $\alpha$-amylase through a disorder $\rightarrow$ order transition of the substrate-binding site mediated by a calcium-sodium-calcium metal triad. Structure 6: 281-292.

Machius M, Wiegand G, Huber R (1995) Crystal structure of calciumdepleted Bacillus licheniformis $\alpha$-amylase at $2.2 \AA$ resolution. $J \mathrm{Mol}$ Biol 246: 545-559.

Machius M, Declerck N, Huber R, Wiegand G (2003) Kinetic stabilization of Bacillus licheniformis alpha-amylase through introduction of hydrophobic residues at the surface. J Biol Chem 278: 11546-11553.

Miller S, Janin J, Lesk AM, Chothia C (1987) Interior and surface of monomeric proteins. J Mol Biol 196: 641-656.

Muzammil S, Kumar Y, Tayyab S (2000) Anion-induced stabilization of human serum albumin prevents the formation of intermediate during urea denaturation. Proteins: Struct Funct Genet 40: 29-38.

Nagarajan DR, Rajagopalan G, Krishnan C (2006) Purification and characterization of a maltooligosaccharide-forming alpha-amylase from a new Bacillus subtilis KCC103. Appl Microbiol Biotechnol 73: 591-597.

Naoe K, Noda K, Kawagoe M, Imai M (2004) Higher order structure of proteins solubilized in AOT reverse micelles. Colloid Surface B 38: 179-185.

Nazmi AR, Reinisch T, Hinz H-J (2006) Ca-binding to Bacillus licheniformis $\alpha$-amylase (BLA). Arch Biochem Biophys 453: 18-25.

Pace CN (1995) Evaluating contribution of hydrogen bonding and hydrophobic bonding to protein folding. Methods Ensymol 259: 538554.

Pace CN (2009) Energetics of protein hydrogen bonds. Nat Struct Mol Biol 16: 681-682.

Pace CN, Scholtz JM (1997) Measuring the conformational stability of a protein. In Protein structure: a practical approach. Creighton TE, ed, pp 299-321. Oxford University Press, New York.

Pandey A, Nigam P, Soccol CR, Soccol VT, Singh D, Mohan R (2000) Advances in microbial amylases. Biotechnol Appl Biochem 31: 135-152.

Qin W, Smith JB, Smith DL (1992) Rates of carbamylation of specific lysyl residues in bovine $\alpha$-crystallins. J Biol Chem 267: 26128-26133.

Salahuddin P (1991) Isolation and characterization of alpha-1-proteinase inhibitor from goat plasma. Biochem Mol Biol Int 24: 321-338.

Serrano L, Horovitz A, Avron B, Bycroft M, Fersht AR (1990) Estimating the contribution of engineered surface electrostatic interactions to protein stability by using double-mutant cycles. Biochemistry 29: 9343-9352.

Shaw BF, Schneider GF, Bilgicer B, Kaufman GK, Neveu JM, Lane WS, Whitelegge JP, Whitesides GM (2008) Lysine acetylation can generate highly charged enzymes with increased resistance toward irreversible inactivation. Protein Sci 17: 1446-1455.

Singh K, Bhakuni V (2008) Toxoplasma gondii ferredoxin-NADP ${ }^{+}$ reductase: Role of ionic interactions in stabilization of native conformation and structural cooperativity. Proteins: Struct Funct Bioinf 71: 1879-1888.

Stark GR (1967) Modification of proteins with cyanate. Methods Ensymol 11: $590-594$.

Tan CY, Raja Abdul Rahman RNZ, Kadir HA, Tayyab S (2010) Calcium-induced stabilization of $\alpha$-amylase against guanidine hydrochloride denaturation. Afr J Biotech 9: 7934-7941.

Tayyab S, Haq SK, Sabeeha, Aziz MA, Khan MM, Muzammil S (1999) Effect of lysine modification on the conformation and indomethacin binding properties of human serum albumin. Int J Biol Macromol 26: $173-180$.

Tayyab S, Qamar S, Islam M (1991) Size exclusion chromatography and size exclusion HPLC of proteins. Biochem Educ 19: 149-152.

Tomazic SJ, Klibanov AM (1988) Why is one Bacillus $\alpha$-amylase more resistant against irreversible thermoinactivation than another? J Biol Chem 263: 3092-3096.

Varavinita S, Chaokasema N, Shobsngobb S (2002) Immobilization of a thermostable alpha-amylase. Sci Asia 28: 247-251.

Vihinen M, Mäntsälä P (1989) Microbial amylolytic enzymes. Crit Rev Biochem Mol Biol 24: 329-418.

Violet M, Meunier J-C (1989) Kinetic studies of the irreversible thermal inactivation of Bacillus licheniformis $\alpha$-amylase. Biochem J 263: 665-670.

Yadav SC, Jagannadham MV (2009) Complete conformational stability of kinetically stable dimeric serine protease milin against $\mathrm{pH}$, temperature, urea, and proteolysis. Eur Biophys J 38: 981-991. 